\title{
Article \\ Body Mass Index, Physical Activity, and Body Image in Adolescents
}

\author{
Marja H. Leppänen ${ }^{1,2, * \mathbb{C}}$, Aku-Ville Lehtimäki ${ }^{1}$, Eva Roos ${ }^{1,3}{ }^{(\mathbb{C}}$ and Heli Viljakainen ${ }^{1,2}$ (C) \\ 1 Folkhälsan Research Center, Topeliuksenkatu 20, 00250 Helsinki, Finland; \\ aku-ville.lehtimaki@folkhalsan.fi (A.-V.L.); eva.roos@folkhalsan.fi (E.R.); heli.viljakainen@helsinki.fi (H.V.) \\ 2 Faculty of Medicine, University of Helsinki, P.O. Box 20, 00014 Helsinki, Finland \\ 3 Department of Food Studies, Nutrition and Dietetics, Uppsala University, P.O. Box 256, \\ SE-751 05 Uppsala, Sweden \\ * Correspondence: Marja.leppanen@folkhalsan.fi; Tel.: +358-44-7881067
}

check for updates

Citation: Leppänen, M.H.; Lehtimäki, A.-V.; Roos, E.; Viljakainen, H. Body Mass Index, Physical Activity, and Body Image in Adolescents. Children 2022, 9, 202. https://doi.org/ 10.3390 / children 9020202

Academic Editor: George

Antonogeorgos

Received: 31 December 2021

Accepted: 31 January 2022

Published: 4 February 2022

Publisher's Note: MDPI stays neutral with regard to jurisdictional claims in published maps and institutional affiliations.

Copyright: (C) 2022 by the authors. Licensee MDPI, Basel, Switzerland. This article is an open access article distributed under the terms and conditions of the Creative Commons Attribution (CC BY) license (https:// creativecommons.org/licenses/by/ $4.0 /)$.

\begin{abstract}
Body image dissatisfaction is a concern for adolescents' mental and physical well-being, and the role of body mass index (BMI) and physical activity (PA) in it is still unclear. This study investigates the associations of BMI and PA with body image, separately for boys and girls, in a large sample of Finnish adolescents. We also examine the associations of BMI with body image in varying PA levels. A total of 10,496 adolescents (girls 52.6\%) were included in the analyses. Body image was assessed using a pictorial tool, and categorized as wishing for a smaller body, being satisfied, and wishing for a bigger body. BMI $\left(\mathrm{kg} / \mathrm{m}^{2}\right)$ was categorized as thin, normal weight, and overweight/obese. Self-reported PA was divided into three similar-sized categories as low, moderate, and high PA levels. Adjusted ordinal regression analyses were conducted. Our results show that adolescents with thinness had higher odds of wishing for a bigger body compared to their normal-weight peers, while adolescents with overweight/obesity had smaller odds of wishing for a bigger body. Adolescents in low and middle PA levels had lower odds of wishing for a bigger body compared to adolescents in the high PA level. Yet, the PA level modified the associations between BMI and body image, especially in adolescents with thinness and more so in girls than in boys. These findings highlight the need to pay attention to healthy weight gain and PA in adolescents to support their body image satisfaction.
\end{abstract}

Keywords: exercise; BMI; body size; children; cohort study

\section{Introduction}

Overweight is a complex condition with multiple contributory causes, including genetic, socioeconomic, environmental, and behavioral factors [1,2]. Over the past four decades, mean body mass index (BMI) and overweight have increased in children and adolescents in most countries worldwide [3]. In Finland, the prevalence of overweight/obesity was $28 \%$ in $7-12$-year-old boys and $18 \%$ in girls in 2019 [4]. These numbers are alarming, since overweight is likely to track into adulthood [5]. Overweight has been associated with multiple physical and psychological consequences, such as an increased risk for cardiovascular diseases and decreased health-related quality of life [6]. Furthermore, a higher BMI has been linked with less favorable body image in young adults [7], which in turn, has been associated with poor psychological health $[8,9]$.

Body image is a multidimensional construct referring to the psychological experience of embodiment, especially, but not exclusively, of one's physical appearance [10]. It reflects how individuals think, feel, see, and act toward their bodies [11]. Body image dissatisfaction has been consistently rated as being among the foremost concerns for young people [12]. Although negative body perceptions have declined in many countries since 2014, every fourth of the adolescents perceive themselves as too fat, especially girls [13]. Body image has implications for one's mental and physical health. For example, perceptions of poor body 
image are related to lower self-esteem [14], higher levels of depression and anxiety [15], and eating disorders [16]. Body image dissatisfaction may also increase the likelihood of obesity [17] as excessive preoccupation with appearance and pursuit of the ideal lean body can produce negative feelings affecting health behavior that will complicate weight management [18]. Nevertheless, concerns about body image have also been linked to reaching the idealized body, which in contemporary Western countries is a thin and a fit physique for females and a lean and muscular physique for males [19].

Physical activity (PA) has been suggested to be one way to achieve a body that resembles cultural expectations [20] and affects positively on body image [21]. A study in 1501 Spanish adolescents reported an inverse correlation between PA and body image, especially regarding moderate-to-vigorous PA [22]. Similar findings were observed in Poland in 3249 adolescents, and additionally, they reported stronger associations in boys compared to girls [23]. Yet, a study in 404 young adults in the USA found a positive correlation between body image and light PA, but not with moderate-to-vigorous PA [24]. BMI was controlled in all these studies indicating an independent role of PA in body image [22-24]. However, there is a lack of studies investigating how PA modifies associations of body image in different BMI categories in adolescents. As the role of weight status in body image may be different depending on the BMI category [21], increasing knowledge about how different levels of PA are related to these associations is important. Such information would help targeting supporting actions effectively on adolescents taking both BMI and PA into account in improving positive body image. Therefore, we aimed to examine associations of BMI and PA with body image in a large sample of 9 to 12-year-old Finnish adolescents. In addition, we examined whether the associations between body image and BMI are different in varying PA levels. The analyses were provided separately for boys and girls due to the previously reported sex differences [22].

\section{Materials and Methods}

\subsection{Study Design and Participants}

The present cross-sectional study utilized baseline data from the Finnish Health in Teens (Fin-HIT) cohort study conducted 2011-2014. Participants consisted of 11,407 adolescents at the age of 9 to 12 years from 44 municipalities, close to Finland's largest cities: Helsinki, Turku, Espoo, Oulu, Jyväskylä, Tampere, and Kuopio. Briefly, the study was mainly carried out in a school setting without specific exclusion criteria [25]. Recruitment and data collection occurred in total in 496 schools and the response rate was $36 \%$. Participating families were highly educated ( $55 \%$ had a university degree, $n=5834)$. An informed written consent was obtained from all adolescents and from one of their caregivers/parents. The study protocol was approved by the Coordinating Ethics Committee of the Hospital District of Helsinki and Uusimaa, Finland (Nr: 169/13/03/00/10). In this study, all adolescents with complete baseline information on body image, BMI, and PA were included $(\mathrm{N}=10,496$, girls $52.6 \%)$.

\subsection{Body Image}

A pictorial tool was used in evaluating body image, and it has been described in detail elsewhere [26]. In brief, the tool consisted of seven, numbered, sex-specific images illustrating body sizes ranging from very thin (number 1) to obese (number 7) [27]. Participants were asked: (1) which of the pictures most resembled your current body shape, and (2) which of the pictures most resembled the body shape you wanted. Based on their responses, the difference between the wanted and current body shape was calculated, and further, categorized into three groups: wishing for a smaller body, satisfied, and wishing for a bigger body. The group wishing for a smaller body included those who wished for a body shape that was smaller than the current one; the satisfied group included those who did not want a different body shape than their current one; and wishing for a larger body group included those who wished for a body shape that was larger than the current one. 


\subsection{Anthropometry}

Weight (in $\mathrm{kg}$ ) and height (in $\mathrm{m}$ ) were measured by trained fieldworkers at schools with portable, daily-calibrated digital scales and a portable stadiometer. BMI was calculated as weight $(\mathrm{kg}) /$ height $\left(\mathrm{m}^{2}\right)$, and it was further categorized as thin, normal weight, overweight, and obese according to Cole and Lobstein [28]. That reference system was chosen because it is concordant with the Finnish reference values [29,30]. The category of obese adolescents was small $(2.6 \%)$; therefore, overweight and obese were combined.

\subsection{Physical Activity}

PA was assessed using a question adapted from another Finnish school-based study [31]. The question was: "How many hours a week do you normally exercise or do sports during your free time? Include all the exercise you do in a club or team and any exercise by yourself, with family or friends. Do not count any exercise at school or on the way to school." The response alternatives were ranging from (1) An hour a week or less to (10) Around ten hours a week. The question was targeted only to leisure-time PA, since it was intended to be easy to report. Moreover, leisure-time PA has been reported to cover the majority of the adolescents ${ }^{\prime}$ daily PA in Finland [32]. In the analyses, PA was recategorized into three similar-sized categories as the following: (1) around $5 \mathrm{~h}$ a week or less (low PA level), (2) around 6-8 h per week (moderate PA level), (3) around $9 \mathrm{~h}$ per week or more (high PA level).

\subsection{Other Background Data}

Sex and age (in years) of participants were confirmed by linkage with the National Population Information System at the Population Register Centre, Finland. Pubertal stage was self-assessed using the Tanner scale [33] and categorized into three groups: prepubertal, pubertal, and post-pubertal.

\subsection{Statistical Analysis}

Descriptive information is presented as means and standard deviation (SD) or frequencies (\%). Sex comparisons were made by t-test for continuous variables and Chi-square test for categorized variables, except Fisher's exact test for pubertal stage due to the small sample size in the post-pubertal stage. Furthermore, Fisher's exact test was used to test differences in BMI and PA categories across body image satisfaction (i.e., wishing for a smaller body, satisfied, wishing for a bigger body). An ordinal regression analysis was conducted first to examine the association of body image with (1) BMI and (2) PA, and secondly, to examine the association of body image with BMI stratified by PA level. Body image was ordered from the lowest to the highest as wishing for a smaller body, satisfied, and wishing for a bigger body. Since ordinal logistic regression was used, it was assumed that body image is actually a (latent) continuous variable, which has been only measured as a three-categorical variable; therefore, BMI and PA predict the changes in the latent continuous scale. Regarding BMI analyses, normal weight was used as a reference category, and regarding PA, the high PA level was used as a reference category. All models were adjusted for the child's age and pubertal stage. The SPSS statistical software (version 26.0) was used for all statistical analyses, and a significance level was set to $5 \%$. The figures were created using R package ggplot2.

\section{Results}

Table 1 shows the characteristics of the 10,496 participating adolescents by sex. In general, boys had a lower pubertal stage, they were more satisfied with their body image, they were more often of normal weight, and had more PA compared to girls. 
Table 1. Characteristics of participating adolescents $(\mathrm{N}=10,496)$

\begin{tabular}{lccccc}
\hline & \multicolumn{2}{c}{ Boys } & \multicolumn{2}{c}{ Girls } & \multirow{2}{*}{$p$-Value $^{\text {a }}$} \\
\cline { 2 - 5 } & $\mathbf{N}$ & Mean (SD)/\% & $\mathbf{N}$ & Mean (SD)/\% & \\
\hline Age, years & 4980 & $11.2(0.84)$ & 5516 & $11.1(0.85)$ & 0.34 \\
\hline Pubertal stage & & & & & $<0.001$ \\
$\quad$ Pre-pubertal & 1381 & 36.4 & 1477 & 32.4 & \\
$\quad$ Pubertal & 2381 & 62.8 & 3022 & 66.4 & $<0.001$ \\
$\quad$ Post-pubertal & 31 & 0.8 & 53 & 1.2 & \\
Body image satisfaction & & & & & \\
$\quad$ Wishing for smaller body & 1358 & 27.3 & 1788 & 32.4 & \\
$\quad$ Satisfied & 3125 & 62.8 & 3245 & 58.8 & \\
$\quad$ Wishing for bigger body & 497 & 10.0 & 483 & 8.8 & \\
Body mass index & & & & & \\
$\quad$ Thin & 455 & 9.1 & 701 & 12.7 & \\
$\quad$ Normal weight & 3742 & 75.1 & 4001 & 72.5 & \\
$\quad$ Overweight or obese & 783 & 15.5 & 814 & 14.8 & \\
Physical activity & & & & & \\
$\quad$ Low level & 1599 & 32.1 & 2287 & 41.5 & \\
$\quad$ Moderate level & 1482 & 29.8 & 1718 & 31.1 & \\
$\quad$ High level & 1899 & 38.1 & 1511 & 27.4 & \\
\hline
\end{tabular}

a Sex comparisons were made by t-test for continuous variables and Chi-square test for categorized variables, except Fisher's exact test for pubertal stage. Low PA level indicates PA around $5 \mathrm{~h}$ a week or less, moderate PA level indicates PA around 6-8 h per week, and high PA level indicates PA around $9 \mathrm{~h}$ per week or more.

The majority of boys with thinness $(61 \%, 277$ out of 455$)$ or normal weight $(71 \%, 2639$ out of 3742) were satisfied with their body image, while $73 \%$ (568 out of 783 ) of boys with overweight wished for a smaller body (Table 2). Similarly, the majority of girls with thinness $(60 \%, 422$ out of 701$)$ or normal weight $(66 \%, 2624$ out of 4001$)$ were satisfied with their body, while $75 \%$ (609 out of 814 ) of girls with overweight wished for a smaller body, respectively.

Table 2. Body image satisfaction by body mass index and physical activity categories.

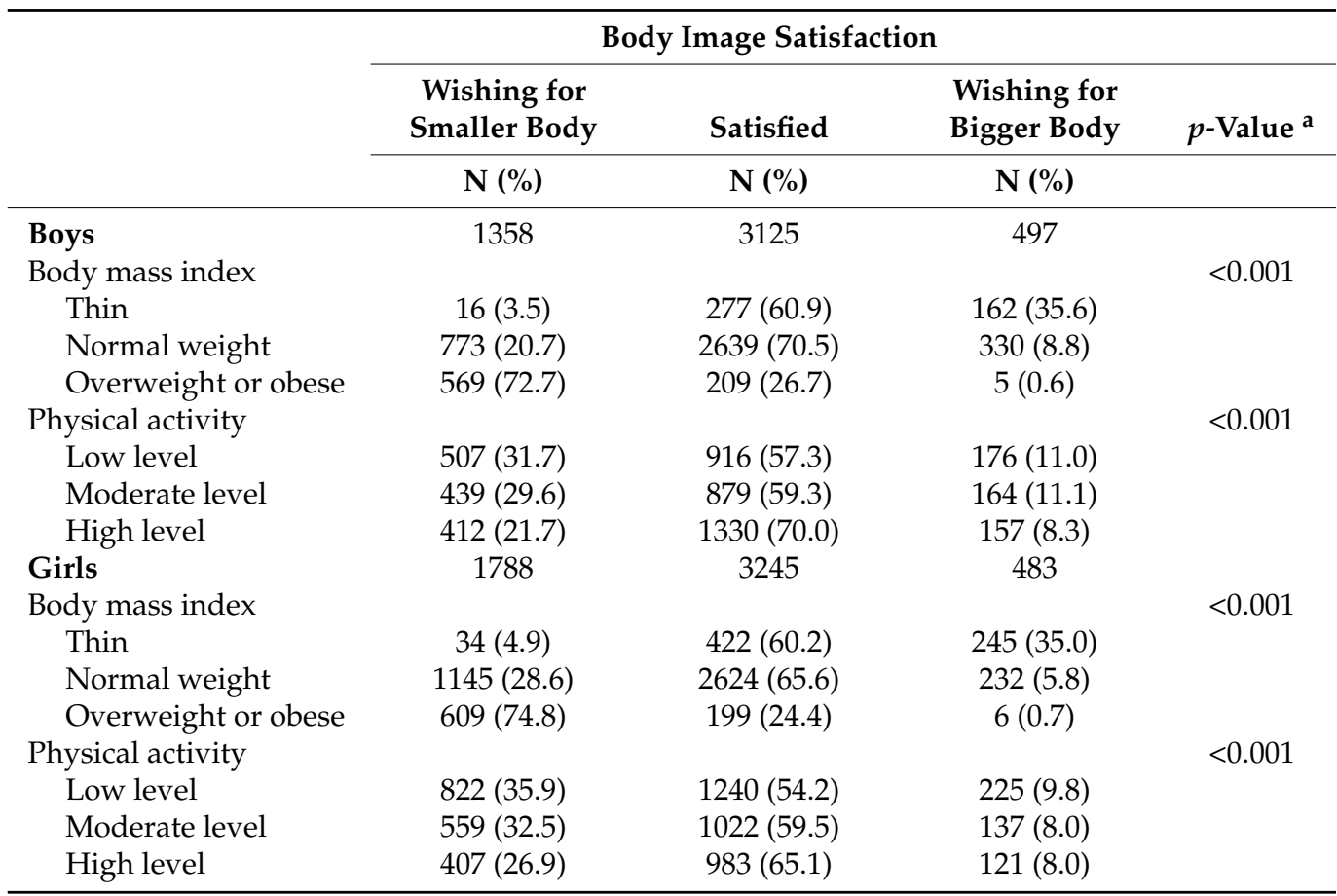

Values are frequencies (N) and percentages (\%). ${ }^{\text {a }}$ Body image satisfaction comparisons were completed using Fisher's exact test. Low PA level indicates PA around $5 \mathrm{~h}$ a week or less, moderate PA level indicates PA around 6-8 h per week, and high PA level indicates PA around $9 \mathrm{~h}$ per week or more. 
The distribution of body image satisfaction differed by PA level both in boys and girls $(p<0.001$ for both) (Table 2$)$. Boys with a high PA level were more satisfied with their body image (70\%) than other boys with lower PA levels (57 and 59\%). Correspondingly, boys with low PA wished for a smaller body more frequently (32\%) than boys with higher PA levels (26\%). Similar observations were noted in girls, with somewhat smaller differences.

\subsection{Association of BMI and PA with Body Image}

Table 3 and Figure 1A,B show that boys and girls with thinness had higher odds of wishing for a bigger body than being satisfied or wishing for a smaller body compared to their counterparts with normal weight (both $p<0.001$ ). In addition, boys and girls with overweight/obesity had smaller odds of wishing for a bigger body than being satisfied or wishing for a smaller body compared to their counterparts with normal weight (both $p<0.001)$.

Table 3. Associations of body mass index and physical activity with body image satisfaction.

\begin{tabular}{|c|c|c|}
\hline & \multicolumn{2}{|c|}{ Body Image Satisfaction } \\
\hline & OR $(95 \% \mathrm{CI})$ & $p$-Value \\
\hline \multicolumn{3}{|l|}{ Boys, $\mathbf{N}=3793$} \\
\hline \multicolumn{3}{|l|}{ Body mass index } \\
\hline Thin & $7.54(5.92,9.60)$ & $<0.001$ \\
\hline Normal weight & Ref. & \\
\hline Overweight or obese & $0.09(0.07,0.11)$ & $<0.001$ \\
\hline \multicolumn{3}{|l|}{ Physical activity } \\
\hline Low level & $0.74(0.63,0.86)$ & $<0.001$ \\
\hline Moderate level & $0.84(0.72,0.99)$ & 0.031 \\
\hline High level & Ref. & \\
\hline \multicolumn{3}{|l|}{ Girls, $N=4552$} \\
\hline \multicolumn{3}{|l|}{ Body mass index } \\
\hline Thin & $9.29(7.56,11.41)$ & $<0.001$ \\
\hline Normal weight & Ref. & \\
\hline Overweight or obese & $0.12(0.10,0.15)$ & $<0.001$ \\
\hline \multicolumn{3}{|l|}{ Physical activity } \\
\hline Low level & $0.79(0.68,0.91)$ & 0.001 \\
\hline Moderate level & $0.84(0.73,0.98)$ & 0.024 \\
\hline High level & Ref. & \\
\hline
\end{tabular}

Boys and girls with low or moderate PA levels had smaller odds of wishing for a bigger body than being satisfied or wishing for a smaller body compared to their counterparts with a high PA level (all $p<0.031$ ) (Table 3, Figure 1A,B).

\subsection{Association of BMI with Body Image Stratified by PA Level}

Table 4 and Figure 2A,B present that boys and girls with thinness had higher odds of wishing for a bigger body than being satisfied or wishing for a smaller body compared to their counterparts with normal weight in all PA levels (all $p \leq 0.001$ ). Furthermore, boys and girls with overweight/obesity had smaller odds of wishing for a bigger body than being satisfied or wishing for a smaller body compared to their counterparts with normal weight in all PA levels (all $p<0.001$ ).

The PA level modified the association between BMI and body image, especially in adolescents with thinness and more clearly in girls than in boys, while the same association was less affected by PA levels among adolescents with overweight. In girls, the lower the PA level, the higher the odds of wishing for a bigger body than being satisfied or wishing for a smaller body compared to their counterparts with normal weight. Whereas in boys 
with thinness, the modifying effect of PA was inconsistent, partly opposite to girls (Table 4 , Figure 2A,B).
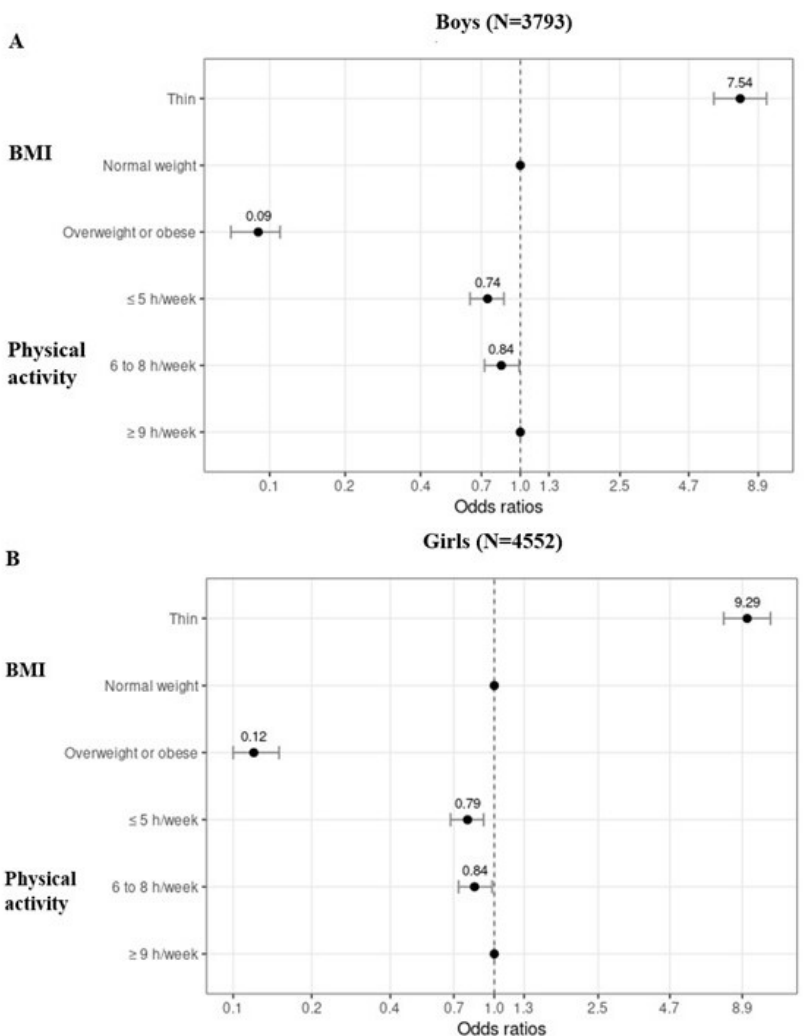

Figure 1. Odds ratios with their $95 \%$ confidence intervals showing the risk for wishing for a bigger body compared to being satisfied or wishing for a smaller body in different body mass index (BMI) and physical activity levels separately for boys (A) and girls (B). Normal weight and $\geq 9 \mathrm{~h} /$ week are reference groups.

Table 4. Associations of body mass index with body image satisfaction stratified by physical activity (PA) level.

\begin{tabular}{|c|c|c|c|}
\hline \multirow[b]{2}{*}{ PA } & \multirow[b]{2}{*}{ BMI } & \multicolumn{2}{|c|}{ Body Image Satisfaction } \\
\hline & & OR $(95 \% \mathrm{CI})$ & $p$-Value \\
\hline \multicolumn{4}{|l|}{ Boys } \\
\hline \multirow{2}{*}{$\begin{array}{l}\text { Low level } \\
(\mathrm{N}=1155)\end{array}$} & Thin & $5.71(3.79,8.61)$ & 0.001 \\
\hline & $\begin{array}{l}\text { Normal weight } \\
\text { Overweight/obese }\end{array}$ & $\begin{array}{c}\text { Ref. } \\
0.10(0.07,0.14)\end{array}$ & $<0.001$ \\
\hline \multirow{3}{*}{$\begin{array}{l}\text { Moderate level } \\
(\mathrm{N}=1147)\end{array}$} & Thin & $9.12(5.94,14.01)$ & $<0.001$ \\
\hline & Normal weight & Ref. & \\
\hline & Overweight/obese & $0.07(0.05,0.11)$ & $<0.001$ \\
\hline \multirow{3}{*}{$\begin{array}{l}\text { High level } \\
(\mathrm{N}=1491)\end{array}$} & Thin & $8.14(5.34,12.01)$ & $<0.001$ \\
\hline & Normal weight & Ref. & \\
\hline & Overweight/obese & $0.10(0.07,0.15)$ & $<0.001$ \\
\hline \multicolumn{4}{|l|}{ Girls } \\
\hline \multirow{2}{*}{$\begin{array}{l}\text { Low level } \\
(\mathrm{N}=1838)\end{array}$} & Thin & $11.82(8.58,16.29)$ & $<0.001$ \\
\hline & $\begin{array}{l}\text { Normal weight } \\
\text { Overweight/obese }\end{array}$ & $\begin{array}{c}\text { Ref. } \\
0.13(0.090 .17)\end{array}$ & $<0,001$ \\
\hline \multirow{3}{*}{$\begin{array}{l}\text { Moderate level } \\
(\mathrm{N}=1459)\end{array}$} & Thin & $9.49(6.60,13.66)$ & $<0.001$ \\
\hline & Normal weight & Ref. & \\
\hline & Overweight/obese & $0.14(0.10,0.20)$ & $<0.001$ \\
\hline \multirow{3}{*}{$\begin{array}{l}\text { High level } \\
(\mathrm{N}=1255)\end{array}$} & Thin & $5.99(3.97,9.02)$ & $<0.001$ \\
\hline & Normal weight & Ref. & \\
\hline & Overweight/obese & $0.10(0.07,0.16)$ & $<0.001$ \\
\hline
\end{tabular}

Values are odds ratios (OR) and 95\% confidence intervals (CI) with their $p$-values from ordinal regression analyses. Body image was ordered from the lowest to the highest as wishing for a smaller body, satisfied, wishing for a bigger body. Regarding BMI analyses, normal weight was used as a reference category. All models were adjusted for child's age and pubertal stage. 
A

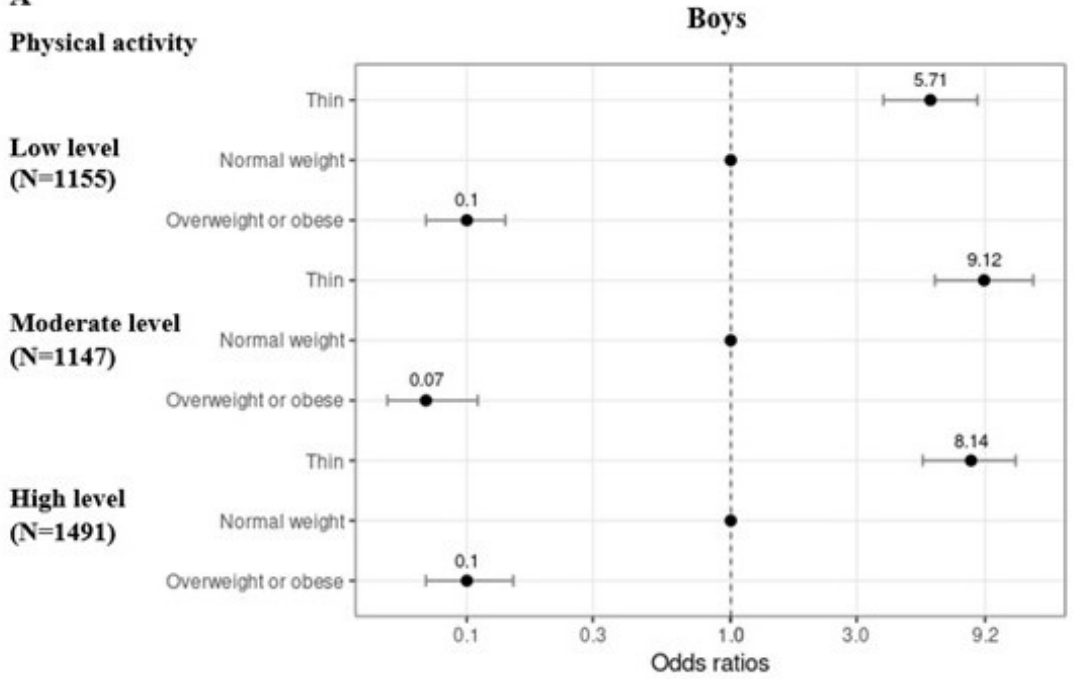

B

Physical activity

Girls

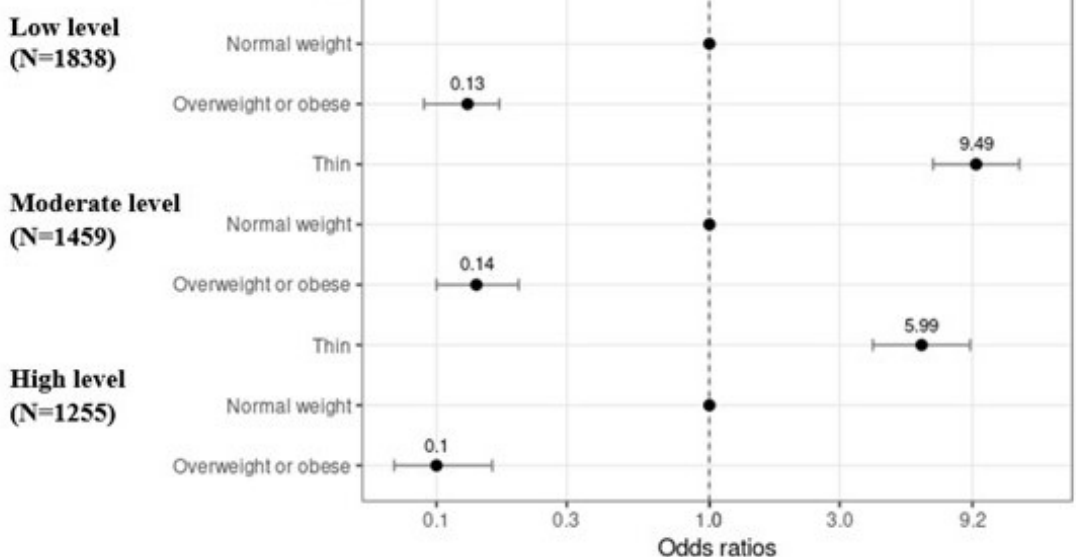

Figure 2. Odds ratios with their $95 \%$ confidence intervals from ordinal regression analyses showing the risk for wishing for a bigger body compared to being satisfied or wishing for a smaller body in different body mass index stratified by physical activity level separately for boys (A) and girls (B). Normal weight is a reference group. Low PA level indicates PA around $5 \mathrm{~h}$ a week or less, moderate PA level indicates PA around 6-8 h per week, and high PA level indicates PA around $9 \mathrm{~h}$ per week or more.

\section{Discussion}

Our study shows that both BMI and PA are associated with body image in 9 to 12-year-old Finnish boys and girls. Although the associations were similar in boys and girls, girls had higher odds of wishing for a different body than their current body compared to boys. In addition, we observed that the PA level modified the associations between BMI and body image especially in adolescents with thinness, and more so in girls than in boys.

In accordance with our results, the adolescents with thinness more commonly wished for a bigger body compared to their normal-weight peers. The associations were similar in boys and girls, but the magnitudes of the associations were stronger in girls compared to boys. This may indicate that girls are more worried about their thinness and wish for a bigger body compared to boys. Girls being more worried about their body image than boys has been reported before [34,35], for instance, due to higher social pressure. Nevertheless, when we took the PA level into account, the girls with thinness had the highest odds of wishing for a bigger body in a low PA level compared to higher PA levels. 
Furthermore, among girls with thinness, the odds of wishing for a bigger body decreased when the PA level increased. Yet, the trend was different in boys with thinness; the odds of wishing for a bigger body was the highest in the moderate PA level and the smallest in the low PA level. Girls with thinness were more satisfied with their body when they were physically more active, possibly due to increased lean body mass. In addition to that, a feeling that the body is improving through PA might be a reason for higher body image satisfaction [21]. In boys with thinness, however, the effect of the PA level was generally more consistent. Our findings are in line with a previous study proposing that PA protects body image satisfaction [35]. However, our study adds an important point of view concerning adolescents with thinness. Often wishing for a smaller body is typical in adolescents [36], but this seems to dependent on the BMI category as suggested before [34]. Thus, BMI should be taken into account when examining relationships with body image satisfaction, and further, planning strategies to improve it. In future studies, it would also be essential to clarify more carefully what kind of body adolescents with thinness are wishing for (e.g., more muscles or more shapes), and do they vary depending on what kind of PA they are engaging in (e.g., strength or endurance training). Furthermore, investigating associations between differences in body composition (such as body fat percentage or lean mass) and body image satisfaction would provide valuable information to health promotion work.

Adolescents with overweight/obesity rarely wished for a bigger body compared to their normal-weight peers, and the magnitudes of the associations were rather consistent in boys and girls. This finding is consistent with the previous study in 234 Portuguese adolescents [35]. Furthermore, the associations were relatively similar in all PA levels suggesting that adolescents with overweight/obesity wished for a smaller body irrespective of their PA level. A previous study has concluded that moderate-to-vigorous PA has been positively related to body image independently of BMI [23]. Furthermore, in terms of wanting to lose weight, body image concerns have been lower in adolescents who participated in PA in which the performance does not depend on appearance or slimness (e.g., basketball or tennis), and in PA in which the performance is not based on appearance but on a lean physical body (e.g., swimming or athletics), as compared to those who participated in PA that aims to improve the physical appearance or for which physical appearance is important to success (e.g., fitness or gymnastics) or to those who were inactive [34]. However, methodological differences in assessing PA make it difficult to compare results between studies, and we, for instance, were not able to examine different PA intensities. Nevertheless, the adolescents in the current study were relatively young and the body image satisfaction may rely more on one's outfit instead of behavior, for instance, due to the different stages of maturity. Therefore, it is possible that the body satisfaction increases "naturally", if overweight declines with age [13]. Yet, our findings highlight the need to pay attention to healthy weight gain in young adolescents in order to support their body image satisfaction.

We also observed that the adolescents in the low PA level had the lowest odds of wishing for a bigger body compared to adolescents in the high PA level. The same trend, although weaker, was seen in adolescents in the moderate PA level compared to adolescents in the high PA level. Since our PA questionnaires concerned only leisure-time, it is possible that the adolescents in the high PA level practiced sports where a bigger body is beneficial; therefore, they wished for it. Yet, our findings are in line with the previous studies in that promoting PA is important in order to support body image satisfaction in adolescents [22,37]. However, since most of the previous studies have been based on self-reported PA [37], the findings should be confirmed using objective measurements in assessing PA in order to be better able to clarify the role of PA. It is possible that different frequencies or intensities of the PA have varying effects on body image. It is also worth it to note that physical attractiveness in boys and athletic identity in both sexes have been positively associated with the intention to be physically active [38] which implies that the associations between PA and perceptions of one's own body might be bidirectional. 
The majority of the boys and girls were satisfied with their body image, and in addition, being a normal weight or having a high PA level were associated with higher body image satisfaction. Yet, four adolescents out of 10 were dissatisfied, and especially being overweight/obese was related to body image dissatisfaction. These findings are concerning, since being dissatisfied with one's own body image may increase the risk for adverse consequences. Adolescents in the current study are in an age when their body shape is changing a lot. They are getting taller but also maturation changes their body and body shape. These changes may affect their body image satisfaction positively or negatively. Since a healthy relationship towards one's own body is essential for physical and mental well-being [14-16], having a positive body image despite being overweight/obesity might prevent some of the long-term consequences of obesity. Although childhood obesity is a major health issue worldwide [3], attention is required also to adolescents with thinness or underweight to support their healthy growth. Encouraging adolescents to be physically active might be one tool to support body image satisfaction.

The strength of the present study is a large sample size, which made it possible to include adolescents across BMI categories (i.e., thin, normal weight, and overweight/obese). Furthermore, the large sample size allowed us to investigate boys and girls separately, which is crucial due to the sex differences in BMI, PA, and body image [22]. Relying on self-reported PA instead of objectively measured PA may be seen as a limitation. In addition, the pictorial tool we used in assessing body image does not allow us to ask about the content of the body, for instance, whether the adolescents wished for more muscles and/or more shapes. Therefore, future studies should address the body image more deeply. However, self-report tools are easy to administer and inexpensive, and thus, more feasible in large-scale studies. Finally, the cross-sectional study design limits the conclusion about causality between the observed associations.

\section{Conclusions}

This study shows that BMI and PA associate with body image satisfaction in a large sample of Finnish 9 to 12-year-old adolescents. Although the associations were similar in boys and girls, girls had higher odds of wishing for a different body than their current body compared to boys. In addition, we observed that the PA level modified the associations between BMI and body image more so in girls than in boys. Our findings highlight the need to pay attention to healthy weight gain in young adolescents in order to support their body image satisfaction, especially in girls. In addition, promoting PA would provide additional benefits. Since BMI influenced whether adolescents wished for a bigger or smaller body, BMI should be taken into account when examining body image in adolescents. Furthermore, in future studies, there is a need to clarify what kind of PA is needed to support body image satisfaction, and additionally, what kind of body image the adolescents are especially wishing for. Such knowledge would help in planning effective actions to improve healthy body image in adolescents.

Author Contributions: Conceptualization, M.H.L. and H.V.; Formal Analysis, M.H.L. and A.-V.L.; Writing-Original Draft Preparation, M.H.L.; Writing—Review and Editing, A.-V.L., E.R. and H.V.; Project Administration, H.V. All authors have read and agreed to the published version of the manuscript.

Funding: This work was supported by the Folkhälsan Research Foundation, Medicinska Understödsföreningen Liv och Hälsa, the Swedish Cultural Foundation in Finland, the Päivikki ja Sakari Sohlberg Foundation, the Finnish Cultural Foundation, and the Signe and Ane Gyllenberg Foundation.

Institutional Review Board Statement: The study was conducted according to the guidelines of the Declaration of Helsinki, and approved by the Institutional Review Board (or Ethics Committee) of The Ethics Committee of the Hospital District of Helsinki and Uusimaa (decision number $169 / 13 / 03 / 00 / 10)$.

Informed Consent Statement: Informed consent was obtained from all subjects involved in the study. 


\begin{abstract}
Data Availability Statement: The data are not publicly available due to research ethical reasons and because the owner of the data is the Samfundet Folkhälsan i svenska Finland r.f. and not the research group. However, the corresponding author can provide further information on the Fin-HIT study and the Fin-HIT data upon a reasonable request.
\end{abstract}

Acknowledgments: The study group thanks the adolescents and parents who were participating in the Fin-HIT Study, the teachers and principals of the schools, and all the fieldworkers and coordinators who took part in cohort enrolment. We also thank Samfundet Folkhälsan i svenska Finland r.f. for supporting the study.

Conflicts of Interest: The authors declare no conflict of interest.

\title{
References
}

1. Qi, L.; Cho, Y.A. Gene-environment interaction and obesity. Nutr. Rev. 2008, 66, 684-694. [CrossRef]

2. $\quad$ Bingham, D.D.; Costa, S.; Hinkley, T.; Shire, K.A.; Clemes, S.A.; Barber, S.E. Physical Activity During the Early Years: A Systematic Review of Correlates and Determinants. Am. J. Prev. Med. 2016, 51, 384. [CrossRef]

3. Collaboration, N.C.D.R.F. Worldwide trends in body-mass index, underweight, overweight, and obesity from 1975 to 2016: A pooled analysis of 2416 population-based measurement studies in 128.9 million children, adolescents, and adults. Lancet 2017, 390, 2627-2642. [CrossRef]

4. Jääskeläinen, S.; Mäki, P.; Mölläri, K.; Mäntymaa, P. Lasten ja Nuorten Ylipaino ja Lihavuus 2019; Terveyden ja Hyvinvoinnin Laitos: Helsinki, Finland, 2020.

5. Bastien, M.; Poirier, P.; Lemieux, I.; Després, J.-P. Overview of epidemiology and contribution of obesity to cardiovascular disease. Prog. Cardiovasc. Dis. 2014, 56, 369. [CrossRef] [PubMed]

6. Pulgarón, E.R. Childhood obesity: A review of increased risk for physical and psychological comorbidities. Clin. Ther. 2013, 35, A18-A32. [CrossRef] [PubMed]

7. Prioreschi, A.; Wrottesley, S.V.; Cohen, E.; Reddy, A.; Said-Mohamed, R.; Twine, R.; Tollman, S.M.; Kahn, K.; Dunger, D.B.; Norris, S.A. Examining the relationships between body image, eating attitudes, BMI, and physical activity in rural and urban South African young adult females using structural equation modeling. PLoS ONE 2017, 12, e0187508. [CrossRef] [PubMed]

8. Mond, J.; Van den Berg, P.; Boutelle, K.; Hannan, P.; Neumark-Sztainer, D. Obesity, Body Dissatisfaction, and Emotional Well-Being in Early and Late Adolescence: Findings From the Project EAT Study. J. Adolesc. Health 2011, 48, 373-378. [CrossRef] [PubMed]

9. Neumark-Sztainer, D.; Paxton, S.J.; Hannan, P.J.; Haines, J.; Story, M. Does Body Satisfaction Matter? Five-year Longitudinal Associations between Body Satisfaction and Health Behaviors in Adolescent Females and Males. J. Adolesc. Health 2006, 39, 244-251. [CrossRef]

10. Cash, T.F. Body image: Past, present, and future. Body Image 2004, 1, 1-5. [CrossRef]

11. Thompson, J.K.; Heinberg, L.J.; Altabe, M.; Tantleff-Dunn, S. Exacting Beauty: Theory, Assessment, and Treatment of Body Image Disturbance; American Psychological Association: Washington, DC, USA, 1999.

12. Bullot, A.; Cave, L.; Fildes, J.; Hall, S.; Plummer, J. Mission Australia: Youth Survey Report 2017; Mission Australia: Sydney, Australia, 2017.

13. Inchley, J.; Currie, D.B.; Budisavljevic, S.; Torsheim, T.; Jåstad, A.; Cosma, A.; Kelly, C.; Mar Arnasson, A. Spotlight on Adolescent Health and Well-Being. Findings from the 2017/2018 Health Behaviour in School-Aged Children (HBSC) Survey in Europe and Canada; WHO Regional Office for Europe: Copenhagen, Denmark, 2020.

14. Miller, C.T.; Downey, K.T. A Meta-Analysis of Heavyweight and Self-Esteem. Personal. Soc. Psychol. Rev. 1999, 3, 68-84. [CrossRef]

15. Stice, E.; Whitenton, K. Risk Factors for Body Dissatisfaction in Adolescent Girls. Dev. Psychol. 2002, 38, 669-678. [CrossRef] [PubMed]

16. Polivy, J.; Herman, C.P. Causes of Eating Disorders. Annu. Rev. Psychol. 2002, 53, 187-213. [CrossRef] [PubMed]

17. Schwartz, M.B.; Brownell, K.D. Obesity and body image. Body Image 2004, 1, 43-56. [CrossRef]

18. de-Magistris, T.; López-Galán, B.; Caputo, V. The Impact of Body Image on the WTP Values for Reduced-Fat and Low-Salt Content Potato Chips among Obese and Non-Obese Consumers. Nutrients 2016, 8, 830. [CrossRef]

19. Brownell, K.D. Dieting and the search for the perfect body: Where physiology and culture collide. Behav. Ther. 1991, 22, 1-12. [CrossRef]

20. Loland, N.W. The Aging Body: Attitudes Toward Bodily Appearance among Physically Active and Inactive Women and Men of Different Ages. J. Aging Phys. Act. 2000, 8, 197-213. [CrossRef]

21. Campbell, A.; Hausenblas, H.A. Effects of Exercise Interventions on Body Image. J. Health Psychol. 2009, 14, 780-793. [CrossRef]

22. Añez, E.; Fornieles-Deu, A.; Fauquet-Ars, J.; López-Guimerà, G.; Puntí-Vidal, J.; Sánchez-Carracedo, D. Body image dissatisfaction, physical activity and screen-time in Spanish adolescents. J. Health Psychol. 2018, 23, 36-47. [CrossRef]

23. Kantanista, A.; Osiński, W.; Borowiec, J.; Tomczak, M.; Król-Zielińska, M. Body image, BMI, and physical activity in girls and boys aged 14-16 years. Body Image 2015, 15, 40-43. [CrossRef]

24. Faro, J.M.; Whiteley, J.A.; Hayman, L.L.; Napolitano, M.A. Body Image Quality of Life Related to Light Physical Activity and Sedentary Behavior among Young Adults with Overweight/Obesity. Behav. Sci. 2021, 11, 111. [CrossRef] 
25. Figueiredo, R.A.O.; Simola-Ström, S.; Rounge, T.B.; Viljakainen, H.; Eriksson, J.G.; Roos, E.; Weiderpass, E. Cohort Profile: The Finnish Health in Teens (Fin-HIT) study: A population-based study. Int. J. Epidemiol. 2019, 48, 23-24. [CrossRef] [PubMed]

26. Figueiredo, R.A.D.O.; Simola-Ström, S.; Isomaa, R.; Weiderpass, E. Body dissatisfaction and disordered eating symptoms in Finnish preadolescents. Eat. Disord. 2018, 27, 34-51. [CrossRef] [PubMed]

27. Collins, M.E. Body figure perceptions and preferences among preadolescent children. Int. J. Eat. Disord. 1991, 10, 199-208. [CrossRef]

28. Cole, T.J.; Lobstein, T. Extended international (IOTF) body mass index cut-offs for thinness, overweight and obesity. Pediatric Obes. 2012, 7, 284-294. [CrossRef] [PubMed]

29. Sarkkola, C.; Viljakainen, J.; de Oliveira Figueiredo, R.A.; Saari, A.; Lommi, S.; Engberg, E.; Viljakainen, H. Prevalence of thinness, overweight, obesity and central obesity in Finnish school-aged children: A comparison of national and international reference values. Obes. Facts 2021. [CrossRef] [PubMed]

30. Saari, A.; Sankilampi, U.; Hannila, M.-L.; Kiviniemi, V.; Kesseli, K.; Dunkel, L. New Finnish growth references for children and adolescents aged 0 to 20 years: Length/height-for-age, weight-for-length/height, and body mass index-for-age. Ann. Med. 2011, 43, 235-248. [CrossRef] [PubMed]

31. Asanti, R.; Oittinen, A. Liikunnasta hyvinvointia ja viihtyvyyttä kouluun. In Turun Koulut Liikkeelle-Hankkeen Väliraportti; Kirjapaino Uusi Aura: Raisio, Finland, 2006.

32. Kokko, S.; Martin, L.; Husu, P.; Villberg, J.; Mehtälä, A.; Jussila, A.-M.; Tynjälä, J.; Vasankari, T.; Ng, K.; Tokola, K.; et al. Lasten ja Nuorten Liikuntakäyttäytyminen, Suomessa: LIITU-Tutkimuksen Tuloksia 2018. Available online: https://jyx.jyu.fi/handle/12 3456789/65854 (accessed on 7 December 2021).

33. Tanner, J.M. Growth at Adolescence: With a General Consideration of the Effects of Hereditary and Environmental Factors upon Growth and Maturation from Birth to Maturity; Blackwell Scientific Publications: Oxford, UK, 1962.

34. Fernández-Bustos, J.G.; Infantes-Paniagua, Á.; Gonzalez-Martí, I.; Contreras-Jordán, O.R. Body Dissatisfaction in Adolescents: Differences by Sex, BMI and Type and Organisation of Physical Activity. Int. J. Environ. Res. Public Health 2019, 16, 3109. [CrossRef]

35. Monteiro Gaspar, M.J.; Amaral, T.F.; Oliveira, B.M.P.M.; Borges, N. Protective effect of physical activity on dissatisfaction with body image in children-A cross-sectional study. Psychol. Sport Exerc. 2011, 12, 563-569. [CrossRef]

36. Cabaco, A.S.; Urchaga, J.D.; Guevara, R.M.; Moral-García, J.E. Psychopathological Risk Factors Associated with Body Image, Body Dissatisfaction and Weight-Loss Dieting in School-Age Adolescents. Children 2021, 8, 105. [CrossRef]

37. Bassett-Gunter, R.; McEwan, D.; Kamarhie, A. Physical activity and body image among men and boys: A meta-analysis. Body Image 2017, 22, 114-128. [CrossRef] [PubMed]

38. González-Serrano, M.H.; Gómez-Tafalla, A.; Calabuig-Moreno, F. Predictive Variables of Adolescents' Intention to Be Physically Active after Graduation. Is Gender a Conditioning Factor? Int. J. Environ. Res. Public Health 2020, 17, 4308. [CrossRef] [PubMed] 